\title{
O ENSINO DE FONOAUDIOLOGIA NO BRASIL: RETRATO DOS CURSOS DE GRADUAÇÃO
}

\author{
THE TEACHING OF SPEECH THERAPY IN BRAZIL: \\ A PORTRAIT OF THE UNDERGRADUATE COURSES
}

\begin{abstract}
Brunah de Castro Brasil ${ }^{1}$ iD (0000-0002-9550-1988), Erissandra Gomes ${ }^{1}$ iD) (0000-0002-2379-7345) Maria do Rocio Fontoura Teixeira ${ }^{1}$ (DD)
\end{abstract}

\begin{abstract}
${ }^{1}$ Universidade Federal do Rio Grande do Sul, Programa de Pós-Graduação em Educação em Ciências: Química da Vida e Saúde, Porto Alegre, Rio Grande do Sul, Brasil. <brunah.brasil@ufrgs.br>
\end{abstract}

Resumo o presente estudo foi realizado em setembro de 2018, e teve como objetivo verificar o estado atual do ensino de fonoaudiologia no Brasil, por meio da caracterização de seus cursos de graduação. Para tal, foi realizada uma pesquisa documental e descritiva, de abordagem quantitativa e qualitativa. O levantamento de dados ocorreu no portal do Ministério da Educação. Analisaram-se 87 cursos de fonoaudiologia vinculados a instituições de ensino superior públicas $(27,6 \%) \mathrm{e}$ privadas $(72,4 \%)$, num total de 7.044 vagas anuais ofertadas, com carga horária média de 3.681 horas, num prazo de integralização entre oito e dez semestres. Os cursos estavam distribuídos em 23 estados brasileiros, com maior concentração na região Sudeste. A maioria dos cursos teve nota três nos indicadores de qualidade propostos pelo Ministério da Educação. Concluiu-se que o ensino da fonoaudiologia no Brasil é fundamentalmente presencial, privado, distribuído pelo país, com baixa ocupação de vagas - aspecto inferido pelo número pequeno de concluintes quando comparado ao número de vagas ofertadas, carga horária mínima maior nas instituições de ensino superior públicas, cumprida entre oito e dez semestres, bem como apresenta indicadores de qualidade satisfatórios.

Palavras-chave fonoaudiologia; ensino; educação superior; instituições de ensino superior.
Abstract The present study was conducted in September 2018, and had the goal of checking the current state of the teaching of speech therapy in Brazil through a characterization of its undergraduate courses. In order to do so, a documentary and descriptive research was conducted with a quantitative and qualitative approach. Data collection was made through the website of the Brazilian Ministry of Education. We analyzed 87 speech therapy undergraduate courses linked to public $(27.6 \%)$ and private $(72.4 \%)$ higher education institutions, totaling 7,044 slots offered annually, with an average of 3,681 credit hours, and a period of integralization ranging from eight to ten semesters. The courses were distributed among 23 Brazilian states, with a higher concentration in the Southern region of the country. Most courses were graded 3 regarding the indicators of quality proposed by the Ministry of Education. We concluded that the teaching of speech therapy in Brazil is fundamentally in-person, private, distributed throughout the country, with a low rate of students taking the slots, an aspect deduced by the small number of graduates compared with the amount of slots offered, higher credit hours in the public higher education institutions, concluded between eight and ten semesters, and it presents satisfactory quality indicators.

Keywords speech therapy; teaching; higher education; higher education institutions. 


\section{Introdução}

A profissão de fonoaudiólogo tem atuação voltada à comunicação humana e foi regulamentada no Brasil em 1981. A lei que regulamenta a profissão estabelece que o fonoaudiólogo é o profissional “que atua em pesquisa, prevenção, avaliação e terapia fonoaudiológicas na área da comunicação oral e escrita, voz e audição, bem como em aperfeiçoamento dos padrões da fala e da voz" (Brasil, 1981, p. 1).

Ao redor do mundo, esses profissionais apresentam diversas formações. Em alguns países, a atuação prescinde de um curso técnico e, em outros, de cursos de graduação em nível de licenciatura ou bacharelado. Nos Estados Unidos e em Portugal, existem duas carreiras: a de terapeuta da fala e a de audiologista, com cursos de formação diferentes para elas (Prates e Silva, 2011; Santini, 2011). No Brasil, a fonoaudiologia vem de uma prática mesclada entre educação, letras e saúde, baseada, principalmente em seus primórdios, na educação de surdos e na reabilitação de linguagem de pessoas com deficiências ou não (Berberian, 2001; Aarão et al., 2011). A formação acadêmica atual, neste país, passa por um curso superior de bacharelado em fonoaudiologia.

Os primeiros cursos, ainda em nível técnico, surgiram na década de 1960. Alguns autores apontam que o primeiro curso de graduação em fonoaudiologia teve início em 1971, na Universidade Federal de Santa Maria, no Rio Grande do Sul (Berberian, 2001; Danesi e Martinez, 2001). A área acadêmica seguiu desenvolvendo-se nas décadas seguintes até que, nos últimos anos, com incentivos do governo federal, foram criados diversos cursos, ampliando, consequentemente, seu reconhecimento no país e o crescimento acadêmico da área.

Com base na vivência da prática fonoaudiológica e nas poucas discussões sobre a formação dos profissionais da área, bem como considerando a fonoaudiologia uma profissão estabelecida oficialmente há pouco tempo, mas com uma história de formação relativamente antiga, entendeu-se ser de suma importância traçar os caminhos da formação acadêmica da área no Brasil. Assim, o objetivo do estudo que deu origem a este $\operatorname{artigo~}^{1}$ foi verificar o estado atual do ensino de fonoaudiologia no país, por meio da caracterização de seus cursos de graduação levando-se em conta a modalidade oferecida, o quantitativo de cursos, a carga horária mínima e o prazo de integralização desta, localização, oferta de vagas e indicadores de qualidade do MEC, considerando-se, para todos esses critérios, o tipo de administração da instituição de ensino superior (IES) que sedia o curso. 


\section{A prática fonoaudiológica}

O início da prática fonoaudiológica no Brasil data do final do século XIX e início do século XX. A situação histórico-social nesse período e até meados da década de 1940 mostrava, no Brasil, ideais higienistas, a constituição da Escola Nova e a necessidade de consolidação da língua nacional - o português. Nesse momento, o ensino torna-se obrigatório, assim como o controle de frequência e o fechamento das escolas estrangeiras, pois estas poderiam, na visão dos governantes da época, interferir na força da língua nacional. $\mathrm{O}$ objetivo era também a uniformização do povo, alcançando-se, assim, a identidade nacional (Berberian, 2001; Aarão et al., 2011).

Para que o país progredisse, era necessário que todos tivessem os mesmos valores culturais e sociais, ou seja, as minorias deveriam se adaptar aos valores dos grupos mais influentes na sociedade. Era preciso ter a população controlada para que todos trabalhassem em prol do mesmo objetivo. Na escola ocorreriam mudanças de atitudes e de visão, pois é um local de possível reprodução e validação da dominação pelas classes dominantes da sociedade e, consequentemente, das desigualdades sociais (Nogueira e Nogueira, 2006; Bourdieu e Passeron, 2014). A padronização da língua foi um dos principais instrumentos de moralização da população, bem como o papel higienista, que levou a medicalização e a psicologização ao ambiente escolar.

O conceito de biopolítica, como descrito por Michel Foucault, atua sobre a população com estratégias globalizantes. É um conjunto de saberes sobre a população que geram estratégias e políticas de intervenção, assim como produzem conhecimento, com o objetivo de dominar os sujeitos, governar os corpos. É necessário conhecer não só os sujeitos que serão atingidos como também dados da população na qual se inserem. Assim, entende-se a biopolítica como um conjunto de relações de poder que enquadra a subjetivação dos indivíduos (Foucault, 1999; Fonseca, 1995; Castro, 2006).

A disciplina, para Foucault, como uma técnica de exercício de poder direcionada ao indivíduo, é aperfeiçoada, nos séculos XVII e XVIII, para uma nova técnica de gestão dos homens. Um sujeito disciplinado é um sujeito subjetivado. Para atingirmos um grupo, primeiro conhecemos os sujeitos que são atores deste e, então, lançamos mãos de estratégias de biopoder. As tecnologias de disciplina e de biopolítica se articulam para o governo da vida e do corpo (Foucault, 1999).

Assim, nas escolas, eram tratados como doenças os sotaques, as variações dialetais, as dificuldades de fala e de linguagem, reconhecidos individualmente, mas agrupados para que atuassem as biopolíticas propostas. Dessa forma, nasce o trabalho de profissionais, chamados na época de logopedistas 
ou ortofonistas, para o tratamento das alterações da língua, buscando uma "normatização da linguagem" (Berberian, 2001, p. 266). A fonoaudiologia nasce, então, da prática, do empirismo e interdisciplinar. Constitui-se como uma atuação profissional da área da saúde mesclada a práticas pedagógicas, no ambiente escolar, com o objetivo de unificar a língua do país e padronizá-la. É uma profissão considerada como paramédica, pertencente à área da saúde, mas com grande inserção na área da educação e das letras, pelo trabalho desenvolvido em relação à linguagem dos sujeitos (Berberian, 2001, 2007; Oliveira, 2002; Aarão et al., 2011).

O trabalho do fonoaudiólogo era primeiramente realizado em escolas e com suporte de pedagogos ou educadores especiais, bem como de professores de séries iniciais. Havia, ainda, outra linha de trabalho fonoaudiológico construída com apoio de médicos otorrinolaringologistas, na realização de exames audiológicos (Berberian, 2001; Danesi e Martinez, 2001).

O campo científico da fonoaudiologia foi constituído mediante lutas (científicas e políticas) estabelecidas nos campos de educação, saúde e letras. Esse campo está em movimento, ou seja, transformando-se a todo momento pela dinâmica de distribuição do capital científico entre seus agentes e instituições, os quais estabelecem relações e lutas para validá-lo e ele receber reconhecimento. O estabelecimento do campo depende da força das relações, da estrutura do campo e da distribuição do capital de reconhecimento científico de agentes e instituições. A autonomia do campo depende da força e das relações estabelecidas pelos agentes e instituições participantes em relação a outros campos científicos. Por autonomia, Bourdieu define o aspecto de não corrupção do campo por interesses políticos e econômicos (Bourdieu, 1983, 2004, 2008).

A década de 1960 foi muito importante para a institucionalização acadêmica e a organização da fonoaudiologia como profissão, principalmente pelo trabalho do médico argentino Julio Bernaldo de Quirós, diretor do Centro Medico de Investigaciones Foniátricas y Audiológicas, responsável pela formação de diversos fonoaudiólogos brasileiros em Buenos Aires (Argentina) e pela promoção de cursos em várias cidades brasileiras, e capacitação de um número grande de profissionais (Figueiredo Neto, 1994; Danesi e Martinez, 2001; Spinelli, 2001; Pupo et al., 2004; Berberian, 2007).

Em 1961, em São Paulo, teve início o primeiro curso de fonoaudiologia, ainda em nível técnico, com duração de um ano, vinculado ao Serviço de Otorrinolaringologia do Hospital das Clínicas. No ano seguinte, vinculado à Clínica de Psicologia da Pontifícia Universidade Católica de São Paulo (PUCSP), foi criado um segundo curso, também técnico, mas com duração de dois anos (Meira, 1998; Pupo et al., 2004; Aarão et al., 2011). A diferença entre os dois cursos era a ênfase do trabalho: enquanto o curso vinculado ao Serviço de Otorrinolaringologia era voltado mais para atividade clínica e questões audiológicas, o curso da PUC-SP trabalhava a reabilitação da linguagem e um 
vínculo maior com profissionais que atuavam na educação (Spinelli, 2001; Pupo et al., 2004; Aarão et al., 2011).

Também na década de 1960, no Rio Grande do Sul, iniciou-se um movimento de reuniões de profissionais, na busca de formar associações. Da reunião destas, surgiu um movimento de reconhecimento da profissão no país, em um trabalho conjunto, principalmente com os estados de São Paulo e Rio de Janeiro. Como resultado, obteve-se, em 1971, a criação do primeiro curso universitário de fonoaudiologia na Universidade Federal de Santa Maria, no Rio Grande do Sul, com funcionamento a partir de 1972; o reconhecimento desse curso em 1975 pelo MEC; e, em 1981, o reconhecimento da profissão de fonoaudiólogo com a lei federal n. 6.965 (Brasil, 1981; Costa, 2001; Danesi e Martinez, 2001).

Ao se levar em conta a hipótese de que, por ser interdisciplinar, o campo científico da fonoaudiologia teria mais possibilidade de desestabilização, percebem-se, nesse caminho trilhado pela área, diversas estratégias de autonomização do campo, tais como a instituição de cursos de graduação, associações de classe, sindicatos e conselhos regionais e federal da profissão. E ainda a tecnicização da profissão e a atuação dos profissionais fonoaudiólogos na rede pública de saúde do país, em diversos municípios, assim como a abertura para inserção de novos profissionais da área nesse setor e em outros tantos (na educação, por exemplo). Atualmente, há mais de 40 mil fonoaudiólogos atuando no Brasil, em 11 diferentes especialidades, de acordo com dados do Conselho Federal de Fonoaudiologia-CFFa (2018).

\section{Caminhos percorridos}

De acordo com Gil (2008), o estudo aqui apresentado caracteriza-se como uma pesquisa documental e descritiva. A análise dos dados é realizada com base em abordagens qualitativa e quantitativa, para compreensão, explicação e análise estatística de dados quantificáveis e não quantificáveis (Gerhardt e Silveira, 2009).

Para o delineamento da amostra, foi realizada uma busca no site do MEC, portal e-MEC (Brasil, 2007a), em setembro de 2018, selecionando os seguintes termos: curso de graduação; curso: fonoaudiologia; modalidade: à distância e presencial; situação: em atividade. Concluída a busca, obteve-se um número de 112 cursos de graduação em fonoaudiologia atualmente em atividade no país. O sistema e-MEC retornou também as seguintes informações: instituição, localização, grau (bacharelado ou licenciatura), modalidade (presencial ou à distância), vagas autorizadas, situação (em atividade ou não) e os indicadores conceito de curso, conceito preliminar de curso (CPC), conceito Enade e índice de diferença entre os desempenhos observado e esperado (IDD). 
Após uma primeira análise, foram excluídos da amostra um curso em processo de extinção voluntária e 24 cursos sem reconhecimento do MEC. Assim, a amostra do estudo foi composta por 87 cursos.

Para análise estatística dos dados, utilizou-se o pacote estatístico SPSS Statistics 22.0. Para as variáveis quantitativas, foram usados valores de média e desvio padrão. Realizou-se teste $t$ de Student para comparação das médias, considerando $\mathrm{p}<0,001$. Para as variáveis qualitativas, foi realizada análise descritiva por meio de medidas de frequência absoluta e relativa.

\section{Os cursos de graduação em fonoaudiologia no Brasil}

Na análise dos dados obtidos, verificou-se que todos os cursos $(n=87)$ são bacharelados em fonoaudiologia e registrados na modalidade presencial. Porém, cabe ressaltar que foram encontrados dois cursos autorizados pelo MEC para funcionamento à distância, ambos em IESs privadas. Esses cursos não fizeram parte da amostra, pois não haviam sido reconhecidos pelo ministério até o momento da coleta de dados.

O funcionamento de cursos à distância na área da saúde é muito questionado, principalmente pelas representações em conselhos profissionais da área, como o CFFa, bem como pela atuação do Fórum dos Conselhos Federais da Área da Saúde. O CFFa manifestou publicamente seu posicionamento contrário à educação à distância (EAD) para a área da saúde, divulgando nota em novembro de 2017 (Teixeira et al., 2013; Conselho Federal de Fonoaudiologia, 2017), e o Conselho Nacional de Saúde se manifestou a partir da resolução n. 515/2016 (Brasil, 2016) contra a EAD na área.

A EAD é um desafio para cursos da saúde, pois ao mesmo tempo que se mostra como uma potencialidade principalmente para cursos de pós-graduação (seja aperfeiçoamento, seja especialização ou mestrado profissional) levanta uma série de questionamentos com relação aos cursos de graduação. Mesmo com práticas de ensino à distância, cursos de graduação na área da saúde exigem práticas clínicas em estágios, o que deve ocorrer em local com infraestrutura adequada (Brasil, 2002; Silva et al., 2015; Koetz, Périco e Grave, 2017; Machado e Ximenes Neto, 2018).

Dos cursos de graduação em fonoaudiologia em atividade e com reconhecimento pelo MEC (num total de 87), 24 (27,6\%) são vinculados a IESs públicas e $63(72,4 \%)$ a IESs privadas. Diversos estudos apontam para o fato de que cerca de $70 \%$ a $80 \%$ das IESs no Brasil são privadas, e no caso dos cursos de fonoaudiologia estudados percebe-se a mesma tendência (Michelotto, Coelho e Zainko, 2006; Haddad et al., 2006, 2010; Costa, Barbosa e Goto, 2011; Griboski, 2012; Machado e Ximenes Neto, 2018).

No que se refere às IESs públicas, verifica-se que, com base na análise dos dados obtidos, de 1968 - registro do primeiro curso mo portal e-MEC ${ }^{2}-$ 
até 2003, ou seja, em 35 anos, houve abertura de 14 cursos. De 2007 até 2013 (último registro de início de atividades em instituições públicas), isto é, em seis anos, registrou-se a abertura de dez cursos. Os dados obtidos são apresentados no Gráfico 1.

Da mesma forma, tais dados corroboram os de Vieira e Moyses (2017), que verificaram um crescimento de $125 \%$ no número de cursos de fonoaudiologia no Brasil entre 1995 e 2015, o que ocorreu também com as outras 13 profissões da área da saúde.

Quanto às IESs privadas, estas seguem a mesma tendência das públicas, porém com uma leve queda no número de cursos abertos na última década, justamente no mesmo período em que se observou um crescimento na abertura de cursos em instituições de ensino superior públicas.

\section{Gráfico 1}

Cursos de fonoaudiologia novos por ano, considerando o tipo de administração das IESs

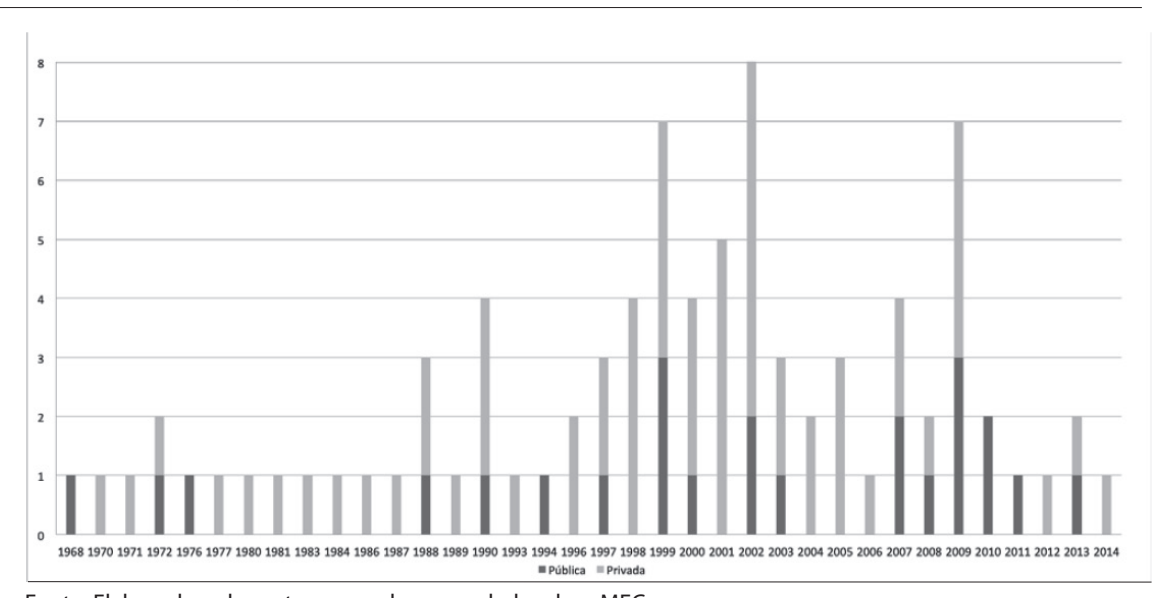

Fonte: Elaborado pelas autoras com base em dados do e-MEC.

Entre os anos de 1970 e 1990 não houve, no país, estímulo à criação de novas IESs privadas, uma vez que verificou-se crescimento muito acentuado no número de instituições nos anos anteriores, focado principalmente em quantidade de cursos diversos e muito pouco na qualidade deles. Dessa forma, o governo cerceou as autorizações de novos cursos e instituições nesse período. A partir de 1990, o crescimento na abertura de IESs privadas é retomado e chega a 151,6\% entre 1996 e 2004 (Michelotto, Coelho e Zainko, 2006).

A partir de 2005, o crescimento observado nas IESs privadas mostra-se relacionado ao investimento realizado pelo governo federal a partir do Programa Universidade para Todos (Prouni) (Brasil, 2005), o qual prevê a concessão de bolsas de estudo em instituições de ensino superior privadas para pessoas que comprovem baixa renda. Ainda por meio do Fundo de Financiamento Estudantil (Fies) (Brasil, 2001), o governo também promoveu o acesso ao en- 
sino superior nessas instituições, financiando o investimento financeiro de famílias de baixa renda (Michelotto, Coelho e Zainko, 2006; Costa, Barbosa e Goto, 2011).

No que se refere a investimento financeiro a IESs públicas, a implantação do Programa de Apoio a Planos de Reestruturação e Expansão das Universidades Federais (Reuni) (Brasil, 2007b), uma ação do Plano de Desenvolvimento da Educação, buscou a expansão do ensino público no país, com o objetivo de ampliar o acesso e garantir a permanência de estudantes, promovendo a retomada do crescimento do ensino superior público. As estratégias adotadas foram aumento de vagas ofertadas, criação de novos cursos - inclusive noturnos -, articulação entre graduação, pós-graduação e ensino técnico, bem como ações pedagógicas e de inovação acadêmica, visando à diminuição da evasão e retenção. Outra meta do programa foi a contratação de pessoal docente e técnico-administrativo para que fosse possível a execução das demais metas, assim como o financiamento de melhorias de infraestrutura (Brasil, 2009a; Costa, Barbosa e Goto, 2011; Teixeira et al., 2013). A partir de ações do Reuni, foi possível inaugurar novas universidades e interiorizar o acesso ao ensino superior público, propondo novos campi àquelas já instaladas.

$\mathrm{O}$ crescimento no número de cursos e ofertas de possibilidades aos indivíduos, como os programas descritos, aumenta a concorrência entre grupos sociais diferentes na propriedade do capital cultural. Porém, isso não diminui as desigualdades sociais, pois os grupos que possuem mais condições - mais capital cultural - modificam suas estratégias e passam a buscar níveis acadêmicos mais altos. Por mais que se democratize o acesso ao ensino superior público, sempre existirá correlação entre desigualdades sociais e culturais e desigualdades nas hierarquias do sistema de ensino (Nogueira e Nogueira, 2006; Bourdieu e Passeron, 2014). Porém, os programas propostos visam também à diminuição das desigualdades, em alguma proporção, quando propõem a interiorização das universidades. Esse acesso, a longo prazo, pode promover mudanças nos contextos sociais nos quais as instituições estão inseridas. Mesmo com a aplicação dos programas citados, as IESs públicas ainda são em número extremamente menor quando comparadas às privadas, o que evidencia a desigualdade social enraizada na cultura do nosso país.

Especificamente sobre o caso da fonoaudiologia, mesmo tendo sido regulamentada há 37 anos, somente nos últimos anos observou-se maior presença da profissão em concursos públicos, proporcionando mais oportunidades no mercado de trabalho. Historicamente, a atuação de fonoaudiólogos ocorria em clínicas ou hospitais privados (Costa, 2001). Tais questões evidenciam a complexidade de implementação de um curso de fonoaudiologia, pois até pouco tempo demandava investimento financeiro considerável, uma vez que se entendia como necessária a instalação, também, de uma clínica-escola para realização das práticas curriculares. Espaço físico, recursos de pessoal e equi- 
pamentos demandam um grande investimento financeiro, algo que foi possível de realização somente por IESs privadas por muitos anos, considerando-se o baixo investimento no ensino superior público do país até o início dos anos 2000. Segundo Michelotto, Coelho e Zainko (2006), os cursos com mais abertura de vagas no país são aqueles que demandam menor investimento em laboratórios e materiais.

As diretrizes curriculares nacionais (DCNs) recomendam que os estudantes da área da saúde devam ter pelo menos $20 \%$ da carga horária total do curso em estágios curriculares e, na sua formação, trabalhar no e pelo sistema de saúde vigente em nosso país. Para trabalhar no Sistema Único de Saúde (SUS) é necessário ir a campo, desbravar os territórios, conhecer os espaços, as cidades e o que há além da universidade (Brasil, 2002).

A partir de 2007 tiveram início dez cursos de fonoaudiologia no Brasil, possivelmente pelo Programa Reuni (Brasil, 2007b) e consequente maior investimento financeiro nas IESs públicas e também pelo maior número de fonoaudiólogos atuando em serviços capazes de receber alunos estagiários, o que permitiu a abertura de cursos sem o investimento condicional em clínicas-escolas (Costa, Barbosa e Goto, 2011), ao se considerarem as DCNs e a proposição do trabalho vinculado ao SUS (Brasil, 2002).

As DCNs estabelecem, ainda, que a formação dos fonoaudiólogos deve ser científica, generalista e crítica, dotando-os de competências e habilidades em atenção à saúde, tomada de decisões, comunicação, liderança, administração, gerenciamento e educação permanente, respondendo ao SUS (Brasil, 2002). Atualmente, temos fonoaudiólogos atuantes em todos os níveis de atenção à saúde, na rede pública, vinculados a núcleos de apoio à saúde da família, centros de reabilitação, hospitais, centros de atenção psicossocial e outros, bem como em instituições de saúde privadas, aumentando cada vez mais a inserção e mostrando a importância do trabalho desse profissional nos diversos cenários de atuação (Costa, 2001; Machado e Ximenes Neto, 2018). Faz-se possível, então, a implementação de cursos de fonoaudiologia com práticas em serviços de saúde externos às universidades, tornando-os menos dispendiosos para a instituição sede e, principalmente, proporcionando ao estudante uma aproximação da população e suas necessidades de saúde, bem como a vivência na prática dos princípios e diretrizes do SUS, numa perspectiva interdisciplinar e desenvolvendo uma relação estreita entre os setores do ensino e da saúde.

A carga horária mínima média dos cursos das IESs públicas é de 4066,83 dp 576,61 horas (mín=3310; máx=5508), e das privadas é de 3535,30dp 355,16 (mín=3200; máx=4428). A média total para o país é de 3681,74 dp 486,66 (mín=3200; máx =5508). Nas instituições de ensino superior públicas, a integralização da carga horária deve ocorrer em oito semestres para 70\% $(\mathrm{n}=16)$ ou dez semestres para 30\% (n=7). Nas IESs privadas, a integralização está prevista para ocorrer em oito semestres para $92 \%$ dos cursos $(n=58)$, nove 
semestres para $5 \%(n=3)$ ou dez semestres para $5 \%(n=2)$. O MEC estabelece o mínimo de 3.200 horas para cursos de fonoaudiologia (Brasil, 2009b). No estudo aqui apresentado, verificou-se que IESs privadas se baseiam no mínimo estabelecido e que as públicas apresentam valores maiores que este.

Constatou-se uma carga horária mínima média menor em IESs privadas, quando comparadas às IESs públicas; e também que a carga horária permanece semelhante para cumprimento em oito e nove semestres e aumenta significativamente para cursos com prazo de integralização em dez semestres $(p=0,000)$.

Quanto à localização no país, verifica-se a presença de cursos de fonoaudiologia em 23 estados brasileiros. Há uma distribuição muito mais homogênea dos cursos de IESs privadas, sendo essa, muitas vezes, a única possibilidade de acesso a cursos de fonoaudiologia em alguns estados. Sobre esse aspecto, Franco e Dal Poz (2017) relatam que houve, nos últimos dez anos, melhor distribuição dos cursos da área da saúde em IESs privadas, principalmente nas regiões Norte e Nordeste.

Nota-se a ausência de cursos públicos na região Norte e a predominância deles na região Sudeste do país - polo nacional consolidado -, seguida da região Nordeste, possivelmente como resultado dos programas de expansão do governo federal aplicados nos últimos 15 anos (Costa, 2001; Brasil, 2009a; Costa, Barbosa e Goto, 2011).

Os dados verificados no estudo aqui apresentado corroboram os de Koetz, Périco e Grave (2017), que analisaram a localização de cursos de fisioterapia no Brasil. Os autores observaram que os cursos se concentram em grandes cidades, principalmente na região Sudeste, e há um número menor de cursos na região Norte. A região Sudeste também é a responsável pelo maior número de profissionais fisioterapeutas.

Em 2017, a oferta de vagas em território nacional foi de 7.044 para cursos de fonoaudiologia, 1.077 nas IESs públicas e 5.967 nas privadas. Os números de concluintes do mesmo curso, nesse ano, foram de 772 e 1.314 para IESs públicas e privadas, respectivamente, perfazendo um total de 2.086 (Inep, 2018b). O Gráfico 2 traz a compilação desses dados, permitindo a visualização de um número extremamente elevado de vagas ofertadas, em comparação com o número de concluintes. Assim, pode-se pensar na possível ociosidade de vagas, fato confirmado quando analisados os dados disponíveis nas estatísticas de 2017 do Instituto Nacional de Estudos e Pesquisas Educacionais Anísio Teixeira (Inep), as últimas publicadas (Meyer Junior, 2005; Inep, 2018b). Os achados são confirmados em outros estudos como os de Franco e Dal Poz (2017) e Haddad e colaboradores (2010), que verificaram que os cursos de fonoaudiologia têm a menor taxa de ocupação de vagas do país $(25,7 \%)$, muito abaixo inclusive da média nacional (50,2\%).

Levanta-se a hipótese de que as IESs públicas têm menos vagas ociosas, pois ofertam um número menor, mais condizente com a procura nas regiões 
em que os cursos estão inseridos. Além disso, nessas instituições há diversas formas de acesso, tais como o vestibular, o sistema de seleção unificada e, ainda, programas de ações afirmativas, como o sistema de cotas.

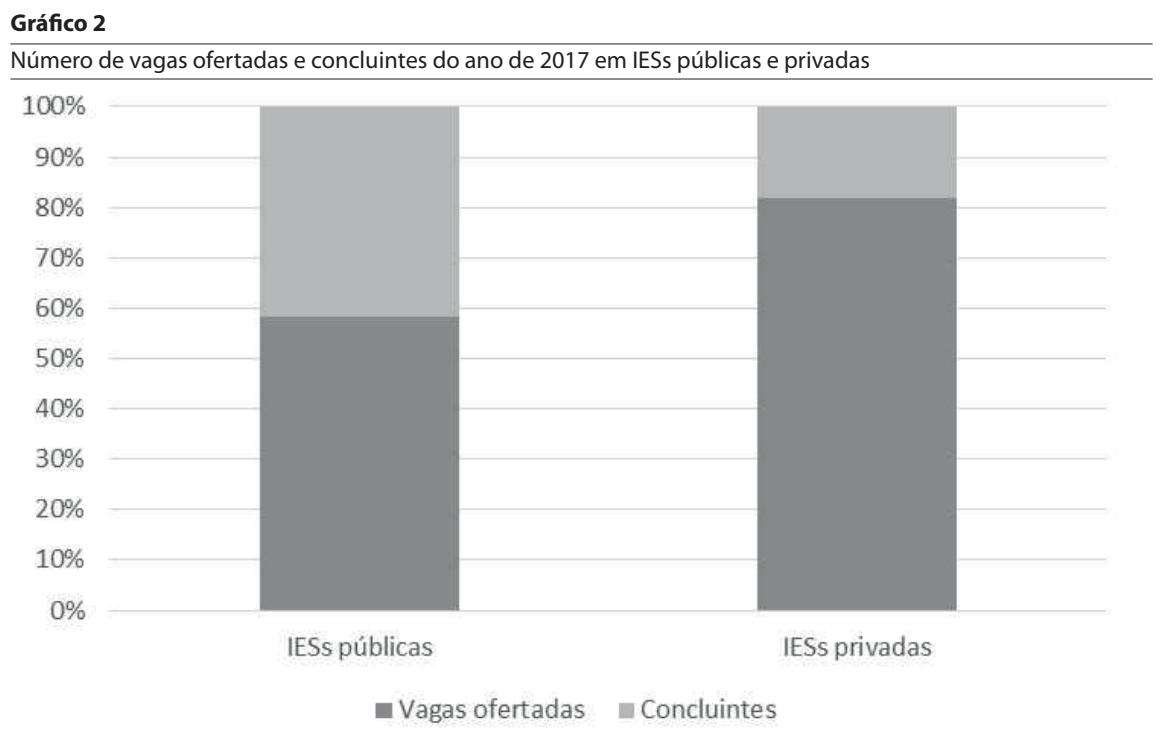

Fonte: Elaborado pelas autoras com base em dados do Inep (2018b).

Ao analisar o número de concluintes e o número de vagas ofertadas, considerando-se o tipo de administração da instituição, verifica-se que o número de vagas ofertado pelas IESs públicas é muito menor quando comparado às privadas, porém, desse número, $71,68 \%$ concluem o curso. O inverso é observado para as privadas, que ofertam um número extremamente elevado de vagas e apenas 22,02\% delas aparecem nas estatísticas no Inep (2018b) como concluintes. Esses achados reforçam a ideia de que o oferecimento de vagas das IESs públicas ocorre de acordo com as necessidades da população, questionando-se se a autorização, pelo MEC, de um número elevado de vagas em IESs privadas faz sentido, uma vez que não são ocupadas. Griboski (2012) observou a mesma tendência para outros cursos de graduação do país, inferindo que nas IESs públicas haveria um número menor de estudantes em situação de evasão.

O número menor de vagas nas IESs públicas, de maneira geral, faz com que a concorrência seja maior, isto é, muitos indivíduos concorrem para um número pequeno de vagas (Taneguti, 2013). Essa concorrência, diz Taneguti (2013), não é observada nas IESs privadas. A capacidade financeira de arcar com mensalidades e materiais e a conciliação de aulas com atividades de trabalho são fatores que podem interferir e prejudicar o acesso de muitos estudantes brasileiros às IESs privadas, os quais também podem ter dificuldades de aderir aos programas Fies e Prouni (pela abrangência destes). Observa-se, então, que 
ainda há desigualdade quando se pensa no ensino superior brasileiro, mesmo com todos os programas oferecidos pelo governo federal.

Atualmente, há 42.420 fonoaudiólogos registrados, distribuídos nas nove regiões de Conselhos Regionais de Fonoaudiologia (Crefonos) do país (Conselho Federal de Fonoaudiologia, 2018). Fez-se uma análise das vagas ofertadas por região dos Crefonos e do número de registros novos anuais de cada região. Ao considerar os dados apresentados na Tabela 1, verifica-se que o número de vagas ofertadas é muito maior do que o número de registros, porém se aproxima do número de concluintes apresentado pelo Inep (2018b), ou seja, cerca de dois mil profissionais novos a cada ano.

\section{Tabela 1}

Vagas ofertadas e registros profissionais novos anuais, por região de Conselhos Regionais de Fonoaudiologia (Crefonos)

\begin{tabular}{lll}
\hline Região & Vagas & Registros novos \\
\hline 1 & 788 & 183 \\
2 & 1.046 & 327 \\
3 & 815 & 174 \\
4 & 970 & 241 \\
5 & 1.152 & 283 \\
6 & 730 & 200 \\
7 & 336 & 114 \\
8 & 596 & 215 \\
9 & 1.330 & $*$ \\
\hline
\end{tabular}

Fonte: Elaborada pelas autoras com base em dados do e-MEC e relatórios de gestão dos Crefonos (2016-2018).

*A 9a região do Crefono foi inaugurada em 2018, portanto não tem, ainda, média de profissionais novos registrados.

\section{Indicadores de qualidade do MEC}

O principal instrumento utilizado pelo MEC para avaliação do ensino superior é o Enade, exame obrigatório que avalia o rendimento dos alunos concluintes em relação aos conteúdos programáticos, habilidades e competências adquiridas durante sua formação, previstos nas DCNs. Avalia ainda o grau de atualização dos estudantes diante da realidade do país e do mundo. Com base na nota nesse exame, o MEC define indicadores de qualidade que caracterizam os cursos autorizados a iniciar atividades, tais como o Conceito Enade, o IDD e o CPC (Brasil, 2018), todos calculados caso o curso possua, no mínimo, dois concluintes participantes do Enade. O Conceito Enade e o IDD são indicadores de desempenho dos estudantes, e o CPC fornece informações sobre os cursos. Há também outro indicador de qualidade dos cursos, o índice geral de cursos avaliados da instituição (IGC). Este não foi utilizado para análise, uma vez que não consta na lista de informações recuperadas no e-MEC. 
O Conceito Enade avalia os cursos pelo desempenho dos estudantes no exame. O IDD mede o valor agregado pelo curso ao desenvolvimento dos estudantes concluintes, considerando o desempenho no Enade e no Exame Nacional do Ensino Médio (Enem). Para que esse indicador seja calculado, os estudantes concluintes participantes do Enade devem possuir, também, informações na base de dados do Enem num período entre o ano de ingresso no curso e os três anos anteriores, bem como atingir $20 \%$ do total de estudantes concluintes participantes do Enade com dados do Enem recuperados (Inep, 2018c). O CPC é calculado no ano seguinte ao da realização do Enade, com base na avaliação de desempenho de estudantes, no valor agregado pelo processo formativo e nas condições do curso, como corpo docente e infraestrutura.

Havia um incômodo das instituições de ensino privadas com relação ao conceito Enade, pois entendiam que, pela dificuldade de acesso, as IESs públicas agregariam um número maior de estudantes de alto rendimento, obtendo notas altas no exame. Para que os resultados de qualidade fossem, então, mais fidedignos, o IDD foi criado, considerando a nota do Enem e, consequentemente, o perfil e a bagagem dos estudantes (Bittencourt et al., 2008).

Todos os indicadores variam de um a cinco e são calculados com base em avaliações de rendimentos dos concluintes e outros aspectos, como infraestrutura física e de pessoal das instituições. São considerados conceitos satisfatórios aqueles iguais ou maiores que três (Brasil, 2008; Inep, 2018c). Os dados coletados para os cursos participantes do estudo foram das avaliações realizadas em 2016, última análise disponibilizada pelo Inep, e estão dispostos na Tabela 2.

Quanto à análise da qualidade dos cursos, tanto IESs públicas como privadas obtiveram conceitos satisfatórios, sem diferenças estatisticamente significantes entre elas. No que se refere ao desempenho dos estudantes, as IESs públicas obtiveram conceito Enade significativamente maior quando comparadas a cursos de instituições privadas, que possuem média insatisfatória nesse indicador. Já para o IDD, considerando-se um índice de resultados mais fidedignos (Bittencourt et al., 2008), o inverso é verificado: as IESs públicas apresentam média insatisfatória no indicador e as IESs privadas satisfatória, porém não se observou diferença entre elas.

Tabela 2

Valores de média e desvio padrão para os indicadores do MEC do ano de 2016, considerando-se o tipo de administração das instituições

\begin{tabular}{lllll}
\hline & Tipo de administração da IES & Média & Desvio padrão & Valor de $\mathbf{p}^{*}$ \\
\hline \multirow{2}{*}{ CPC } & Pública & 3,43 & 0,507 & 0,090 \\
& Privada & 3,14 & 0,866 & \\
\multirow{2}{*}{ Enade } & Pública & 3,33 & 0,856 & $<0,001^{* *}$ \\
& Privada & 2,42 & 0,989 & 0,123 \\
\hline
\end{tabular}

Fonte: Elaborada pelas autoras com base em dados do e-MEC.

Legenda: CPC - conceito preliminar de curso; IDD - indicador de diferença entre os desempenhos observado e esperado; *Teste t de Student; ** estatisticamente significante. 
As hipóteses levantadas para justificar as diferenças encontradas nos dados apresentados são em relação à carga horária dos cursos de IESs públicas, a qual é geralmente maior quando comparada a IESs privadas. Esses indicadores somente são calculados se os cursos tiverem pelo menos dois concluintes - logo, nas IESs privadas, se tivermos vagas ociosas, como indicado anteriormente, podemos ter um número maior de cursos sem atingir o número mínimo de concluintes e sem participar do cálculo desses indicadores.

Os indicadores de qualidade são utilizados pelo MEC para avaliar o ensino superior e regular autorizações e reconhecimentos de cursos, porém ainda é fraco o amparo teórico desses dados para que se possa concluir sobre o desempenho dos alunos (Freire, Crisóstomo e Castro, 2007). Bertoin e Marcon (2015) apontam que, muito além dos indicadores, os contextos familiar, social e cultural são fatores que têm maior influência no desempenho dos estudantes, remetendo ao conceito de capital cultural, de Bourdieu (1983).

\section{Considerações finais}

O panorama dos 87 cursos analisados permite visualizar que o ensino da fonoaudiologia no Brasil é fundamentalmente presencial, privado, distribuído pelo país, com 7.044 vagas ofertadas em 2017, porém com baixa ocupação delas, carga horária mínima maior nas IESs públicas, cumprida entre oito e dez semestres. Após a análise dos dados, percebeu-se que houve avanços do governo federal na tentativa de redução das desigualdades de acesso, com a oferta de novos cursos, principalmente em IESs públicas, em diferentes regiões do país. Os cursos analisados apresentaram indicadores de qualidade satisfatórios, mas alguns dos indicadores de desempenho dos estudantes analisados mostraram conceitos insatisfatórios, sem ficar clara a diferença entre IESs públicas e privadas.

Notou-se, também, que as estratégias de autonomização do campo foram efetivas, com presença atuante dos conselhos regionais e federal na defesa da profissão e a consequente estabilidade do campo no setor acadêmico, considerando-se que ao longo dos anos analisados sempre houve a abertura de cursos. Porém, a presença da desigualdade ainda é observada, seja na distribuição dos cursos, seja no acesso, na ocupação das vagas ou no desempenho dos estudantes, o que nos faz crer que o campo científico da fonoaudiologia - assim como do ensino superior brasileiro - tem muito a evoluir, valendo-se, nesse caso, de suas áreas de base, como educação, letras e saúde, traçando redes e permitindo que essa construção seja constante.

O estudo aqui apresentado buscou contribuir para o desenho acadêmico do campo científico da fonoaudiologia, mapeando o percurso de construção da legitimidade da área, tornando-o reconhecido nacionalmente. Porém, novas pesquisas com aprofundamento na produção desse capital podem ser 
realizadas, para que se visualizem melhor o campo e os atores e instituições que dele fazem parte.

\section{Colaboradoras}

Brunah de Castro Brasil participou da coleta e análise dos dados, descrição e análise dos resultados e elaboração do texto final; Erissandra Gomes orientou a coleta de dados, participou da descrição e análise dos resultados e elaboração do texto final; Maria do Rocio Fontoura Teixeira orientou a coleta de dados, a análise dos resultados e a revisão do texto final. Os autores declaram não haver conflitos de interesse.

\section{LA ENSEÑANZA DE FONOAUDIOLOGIA EN BRASIL: RETRATO DE LOS CURSOS DE GRADUACIÓN}

Resumen El estudio fue realizado en septiembre de 2018, y tuvo como objetivo verificar el estado actual de la enseñanza de fonoaudiología en Brasil, por medio de la caracterización de sus cursos de graduación. Para ello, fue realizada una búsqueda documental y descriptiva, de abordaje cuantitativo y cualitativo. El relevamiento de datos se realizó en el portal del Ministerio de Educación Brasileño. Se analizaron 87 cursos de fonoaudiología vinculados a instituciones de enseñanza superior públicas $(27,6 \%)$ y privadas $(72,4 \%)$, en un total de 7.044 vacantes anuales ofertadas, con carga horaria promedio de 3.681 horas, en un plazo de integralización entre ocho y diez semestres. Los cursos estaban distribuidos en 23 estados brasileños, con mayor concentración en la región Sudeste. La mayoría de los cursos tuvo nota tres en los indicadores de calidad propuestos por el Ministerio de Educación. Se concluyó que la enseñanza de la fonoaudiología en Brasil es fundamentalmente presencial, privado, distribuido por el país, con baja ocupación de vacantes - aspecto inferido por el número pequeño de concluyentes cuando es comparado al número de vacantes ofertadas, carga horaria mínima mayor en las instituciones de enseñanza superior públicas, cumplida entre ocho y diez semestres, así como presenta indicadores de calidad satisfactorios.

Palabras clave fonoaudiología; enseñanza; educación superior; instituciones de enseñanza superior.

\section{Notas}

${ }^{1}$ Este artigo faz parte do projeto de tese intitulado A produção científica da fonoaudiologia brasileira: estudo de caso dos cursos de graduação de instituições públicas de ensino, de autoria de Brunah de Castro Brasil, vinculada ao Programa de Pós-Graduação stricto sensu em Educação em Ciências: Química da Vida e Saúde, Porto Alegre, Rio Grande do Sul. Não houve financiamento para o estudo.

${ }^{2}$ Na bibliografia consultada, o Curso de Fonoaudiologia da Universidade Federal de Santa Maria foi o primeiro de nível superior em atividade. No sistema e-MEC há o registro de início do Curso de Fonoaudiologia da Universidade Federal de São Paulo no ano de 1968, porém, há relatos que de o funcionamento desse curso ainda era em nível técnico, nesse período. Optou-se, neste estudo, por considerar, para as análises realizadas, o início dos cursos superiores em fonaudiologia no ano de 1968, uma vez que resgatou-se todas as demais informações no sistema e-MEC. 


\section{Referências}

AARÃO, Poliane C. L. et al. Histórico da Fonoaudiologia: relato de alguns estados brasileiros. Revista Médica de Minas Gerais, Belo Horizonte, v. 21, n. 2, p. 238-244, 2011.

BERBERIAN, Ana P. Linguagem e Fonoaudiologia: Uma análise histórica. Revista Distúrbios da Comunicação, São Paulo, v. 12, n. 2, p. 265-278, 2001 .

BERBERIAN, Ana P. Fonoaudiologia e educação: um encontro histórico. 2. ed. São Paulo: Plexus, 2007.

BERTOIN, Julio C. G.; MARCON, Telmo. O (des)entendimento de qualidade na educação superior brasileira: das quimeras do provão e do ENADE à realidade do capital cultural dos estudantes. Avaliação, Campinas, v. 20, n. 1, p. 105-122, 2015.

BITTENCOURT, Hélio R. et al. Uma análise da relação entre os conceitos Enade e IDD. Estudos em avaliação educacional, São Paulo, v. 19, n. 40, p. 247-262, 2008.

BOURDIEU, Pierre. O campo científico. In: ORTIZ, Renato (Org.). Pierre Bourdieu: sociologia. São Paulo: Ática, 1983. p. 122-155.

BOURDIEU, Pierre. Os usos sociais da ciência: por uma sociologia clínica do campo científico. São Paulo: UNESP, 2004.

BOURDIEU, Pierre. Para uma sociologia da ciência. Lisboa: Edições 70, 2008.

BOURDIEU, Pierre; PASSERON, JeanClaude. A reprodução. 7. ed. Petrópolis: Vozes, 2014.

BRASIL. Câmara dos Deputados. Centro de Documentação e Informação. Lei n. 6.965, de 9 de dezembro de 1981. Dispõe sobre a regulamentação da profissão de Fonoaudiólogo, e determina outras providências. Diário Oficial da União,
Brasília, DF, 9 dez. 1981. Disponível em: <http://www2.camara.leg.br/legin/fed/ lei/1980-1987/lei-6965-9-dezembro-1981356567-normaatualizada-pl.html>. Acesso em: 20 ago. 2018.

BRASIL. Presidência da República. Casa Civil. Subchefia para Assuntos Jurídicos. Lei n. 10.260, de 12 de julho de 2001. Dispõe sobre o Fundo de Financiamento ao estudante do Ensino Superior e dá outras providências. Diário Oficial da União, Brasília, DF, 13 jul. 2001. Disponível em: <http://www.planalto.gov.br/ ccivil_03/LEIS/LEIS_2001/L10260.htm>. Acesso em: 15 set. 2018.

BRASIL. Ministério da Educação. Conselho Nacional de Educação. Câmara de Educação Superior. Resolução n. 5, de 19 de fevereiro de 2002. Institui Diretrizes Curriculares Nacionais do Curso de Graduação em Fonoaudiologia. Diário Oficial da União, Brasília, DF, 4 mar. 2002. Seção 1, p. 12. 2002.

BRASIL. Presidência da República. Casa Civil. Subchefia para Assuntos Jurídicos. Lei n. 11.096, de 13 de janeiro de 2005. Institui o Programa Universidade para Todos - PROUNI, regula a atuação de entidades beneficentes de assistência social no ensino superior; altera a Lei no 10.891, de 9 de julho de 2004, e dá outras providências. Diário Oficial da União, Brasília, DF, 14 jan. 2005. Disponível em: <http://www.planalto.gov. br/ccivil_03/_Ato2004-2006/2005/Lei/ L1 1096.htm >. Acesso em: 15 set. 2018.

BRASIL. Ministério da Educação. Portaria Normativa n. 40, de 12 de dezembro de 2007. Institui o e-mec, sistema eletrônico de fluxo de trabalho e gerenciamento de informações relativas aos processos de regulação da educação superior no sistema federal de educação. Diário Oficial da União, Brasília, DF, 13 dez. 2007a. Seção 1, p. 39-43. 
BRASIL. Presidência da República. Casa Civil. Subchefia para Assuntos Jurídicos. Decreto n. 6.096, de 24 de abril de 2007. Institui o Programa de Apoio a Planos de Reestruturação e Expansão das Universidades Federais - REUNI. Diário Oficial da União, Brasília, DF, 25 abr. 2007b. Disponível em: <http://www.planalto.gov.br/ ccivil_03/_ato2007-2010/2007/decreto/ d6096.htm >. Acesso em: 10 set. 2018.

BRASIL. Ministério da Educação. Portaria Normativa n. 4 , de 5 de agosto de 2008. Regulamenta a aplicação do conceito preliminar de cursos superiores, para fins dos processos de renovação de reconhecimento respectivos, no âmbito do ciclo avaliativo do SINAES instaurado pela Portaria Normativa $\mathrm{n}^{\circ} 1$, de 2007. Diário Oficial da União, Brasília, DF, 6 ago. 2008. Seção 1, p. 19.

BRASIL. Ministério da Educação. Programa de apoio a planos de reestruturação $e$ expansão das universidades federais Reuni 2008: relatório de primeiro ano. Brasília: Ministério da Educação, 2009a. 17p.

BRASIL. Ministério da Educação. Resolução n. 4 , de 6 de abril de 2009. Dispõe sobre carga horária mínima e procedimentos relativos à integralização e duração dos cursos de graduação em Biomedicina, Ciências Biológicas, Educação Física, Enfermagem, Farmácia, Fisioterapia, Fonoaudiologia, Nutrição e Terapia Ocupacional, bacharelados, na modalidade presencial. Diário Oficial da União, Brasília, DF, 7 abr. 2009b. Seção 1, p. 27.

BRASIL. Conselho Nacional de Saúde. Resolução n. 515, de 7 de outubro de 2016. Diário Oficial da União, Brasília, DF, 11 nov. 2016. Seção 1, p. 61.

BRASIL. Ministério da Educação. Portaria Normativo n. 840, de 24 de agosto de 2018. Dispõe sobre os procedimentos de competência do Instituto Nacional de Estudos e Pesquisas Educacionais Anísio Teixeira referentes à avaliação de institui- ções de educação superior, de cursos de graduação e de desempenho acadêmico de estudantes. Diário Oficial da União, Brasília, DF, 27 ago. 2018. Seção 1, p. 99.

CASTRO, Edgardo. Leituras da modernidade educativa. Disciplina, biopolítica, ética. In: GONDRA, José; KOHAN, Walter O. (org.). Foucault 80 anos. Belo Horizonte: Autêntica, 2006. p. 63-78.

CONSELHO FEDERAL DE FONOAUDIOLOGIA. Nota pública: Contra a graduação à distância na área da saúde. Disponível em: <http://www.fonoaudiologia.org.br/ cffa/index.php/2017/11/nota-publicacontra-a-graduacao-a-distancia-na-areada-saude/>. Acesso em: 10 set. 2018.

\section{CONSELHO FEDERAL DE FONOAUDIOLO-} GIA. Quantitativo de fonoaudiólogos no Brasil em 2018. Disponível em: <http:// www.fonoaudiologia.org.br/cffa/index. $\mathrm{php} /$ numero-por-regiao/>. Acesso em: 4 jul. 2018.

COSTA, Thelma. Fonoaudiologia no Brasil: Perdas e ganhos. Revista Distúrbios da Comunicação, São Paulo, v. 12, n. 2, p. 279-282, 2001.

COSTA, Danilo M.; BARBOSA, Francisco V.; GOTO, Melissa M. M. O novo fenômeno da expansão da educação superior no Brasil. Revista Reuna, Belo Horizonte, v. 16, n. 1, p. 15-29, 2011.

DANESI, Marlene C.; MARTINEZ, Zulmira O. (org.). Reconstrução histórica da fonoaudiologia no Rio Grande do Sul. 1. ed. Porto Alegre: IMEC, 2001.

FIGUEIREDO NETO, Lucia E. Consciência história e identidade profissional. Revista Distúrbios da Comunicação, São Paulo, v. 7, n. 1, p. 71-78, 1994.

FONSECA, Márcio A. Michel Foucault e a constituição do sujeito. São Paulo: EDUC, 1995. 
FOUCAULT, Michel. Direito de morte e poder sobre a vida. In: FOUCAULT, Michel. História da sexualidade 1: a vontade de saber. 13. ed. Rio de Janeiro: Graal, 1999. p. 125-148.

FRANCO, Thais A. V.; DAL POZ, Mario R. A participação de instituições de ensino superior privadas na formação em saúde no Brasil. Trabalho, Educação e Saúde, Rio de Janeiro, v. 16, n. 3, p. 1.0171.037, 2017.

FREIRE, Fátima S.; CRISÓSTOMO, Vicente L.; CASTRO, Juscelino E. G. Análise do desempenho acadêmico e indicadores de gestão das IFES. Revista Produção, Florianópolis, edição especial, 2007.

GERHARDT, Tatiana E.; SILVEIRA, Denise T. Métodos de pesquisa. Porto Alegre: Editora da UFRGS, 2009.

GIL, Antonio C. Métodos e técnicas de pesquisa social. 6. ed. São Paulo: Atlas, 2008.

GRIBOSKI, Claudia M. O ENADE como indutor da qualidade da educação superior. Estudos em Avaliação Educacional, São Paulo, v. 23, n. 53, p. 178-195, 2012.

HADDAD, Ana E. et al. (org.). A trajetória dos cursos de graduação na saúde: 1991 a 2004. Brasília: INEP, 2006.

HADDAD, Ana E. et al. Formação de profissionais de saúde no Brasil: uma análise do período de 1991 a 2008. Revista de Saúde Pública, São Paulo, v. 44, n. 3, p. 383-393, 2010.

INSTITUTO NACIONAL DE ESTUDOS E PESQUISAS EDUCACIONAIS ANÍSIO TEIXEIRA (INEP). ENADE. Disponível em: <http://portal.inep.gov.br/enade $>$. Acesso em: 2 set. $2018 \mathrm{a}$.

INSTITUTO NACIONAL DE ESTUDOS E PESQUISAS EDUCACIONAIS ANÍSIO TEIXEIRA (INEP). Sinopse estatística da educação superior 2017. Brasília: INEP, 2018b. Disponível em: <http://portal.inep. gov.br/web/guest/sinopses-estatisticasda-educacao-superior $>$. Acesso em: 20 set. $2018 \mathrm{~b}$.

INSTITUTO NACIONAL DE ESTUDOS E PESQUISAS EDUCACIONAIS ANÍSIO TEIXEIRA (INEP). Indicadores de Qualidade. Disponível em: <http://inep.gov. $\mathrm{br} /$ web/guest/indicadores-de-qualidade $>$. Acesso em 20 set. $2018 \mathrm{c}$.

KOETZ, Lydia C. E.; PÉRICO, Eduardo; GRAVE, Magali Q. Distribuição geográfica da formação em Fisioterapia no Brasil: Crescimento desordenado e desigualdade social. Trabalho, Educação e Saúde, Rio de Janeiro, v. 15, n. 3, p. 917-930, 2017.

MACHADO, Maria H.; XIMENES NETO, Francisco R. G. Gestão da educação e do trabalho em saúde no SUS: trinta anos de avanços e desafios. Ciência \& Saúde Coletiva, Rio de Janeiro, v. 23, n. 6, p. 1.971-1.980, 2018.

MEIRA, Isis. Breve relato da história da fonoaudiologia no Brasil. In: MARCHEZAN, Irene Q.; ZORZI, Jaime L.; GOMES, Ivone C. D. (org.). Tópicos em fonoaudiologia 1997/1998. São Paulo: Lovise, 1998.

MEYER JUNIOR, Victor. Planejamento universitário: ato racional, político ou simbólico: um estudo de universidades brasileiras. In: ENCONTRO ANUAL DA ANPAD, 28., 2004, Curitiba. Anais... Curitiba: ANPAD, 2004.

MiCHELOTTO, Regina M.; COELHO, Rubia H.; ZAINKO, Maria A. S. A política de expansão da educação superior e a proposta de reforma universitária do governo Lula. Educar, Curitiba, n. 28, p. 179-198, 2006.

NOGUEIRA, Maria A.; NOGUEIRA, Cláudio M. M. Bourdieu \& a educação. 2. ed. Belo Horizonte: Autêntica, 2006.

OLIVEIRA, Fabiana. Por uma terapêutica fonoaudiológica: os efeitos do discurso 
médico e do discurso pedagógico na constituição do discurso fonoaudiológico. 2002. 186f. Dissertação (Mestrado em Estudos da Linguagem) - Instituto de Letras, UFRGS, Porto Alegre, 2002.

PRATES, Andreia; SILVA, Eloísa. A terapia da fala em Portugal. Revista Distúrbios da Comunicação, São Paulo, v. 23, n. 3, p. 365-368, 2011.

PUPO, Altair C. et al. 40 anos do curso de fonoaudiologia na PUC-SP. Revista Distúrbios da Comunicação, São Paulo, v. 16, n. 1, p. 117-124, 2004.

SILVA, Adriane N. et al. Limites e possibilidades do ensino à distância $(\mathrm{EaD})$ na educação permanente em saúde: revisão integrativa. Ciência \& Saúde Coletiva, Rio de Janeiro, v. 20, n. 4, p. 1.0991.107, 2015.

SANTINI, Celia S. "O discurso do rei" ou o futuro da fonoaudiologia. Revista CEFAC, São Paulo, v. 13, n. 3, p. 391584, 2011

SPINELLI, Mauro. Histórico da fonoaudiologia na PUC-SP. Revista Distúrbios da Comunicação, São Paulo, v. 12, n. 2, p. 259-264, 2001 .

TANEGUTI, Luiza Y. Relatório técnico contendo estudo sobre a atual relação oferta/ demanda de cursos de graduação no Brasil, como subsidio ao Conselho Nacional de Educação para a formulação de políticas públicas que possibilitem a melhor distribuição da oferta de vagas no ensino superior de graduação. Brasília: Ministério da Educação, 2013.

TEIXEIRA, Elizabeth et al. Panorama dos cursos de graduação em Enfermagem no
Brasil na década das diretrizes curriculares nacionais. Revista Brasileira de Enfermagem, Brasília, v. 66, n. especial, p. 102-110, 2013.

VIEIRA, Ana L. S.; MOYSES, Neuza M. N. Trajetória da graduação das catorze profissões de saúde no Brasil. Saúde Debate, Rio de Janeiro, v. 14, n. 113, p. 401-414, 2017.

SANTINI, Celia S. 'O discurso do rei' ou o futuro da fonoaudiologia. Revista Cefac, São Paulo, v. 13, n. 3, p. 391-584, 2011.

SILVA, Adriane N. et al. Limites e possibilidades do ensino à distância (EAD) na educação permanente em saúde: revisão integrativa. Ciência \& Saúde Coletiva, Rio de Janeiro, v. 20, n. 4, p. 1.099-1.107, 2015.

SPINELLI, Mauro. Histórico da fonoaudiologia na PUC-SP. Distúrbios da Comunicação, São Paulo, v. 12, n. 2, p. 259-264, 2001.

TANEGUTI, Luiza Y. Relatório técnico contendo estudo sobre a atual relação oferta/demanda de cursos de graduação no Brasil, como subsídio ao Conselho Nacional de Educação para a formulação de políticas públicas que possibilitem a melhor distribuição da oferta de vagas no ensino superior de graduação. Brasília: Ministério da Educação, 2013.

TEIXEIRA, Elizabeth et al. Panorama dos cursos de graduação em enfermagem no Brasil na década das diretrizes curriculares nacionais. Revista Brasileira de Enfermagem, Brasília, v. 66, n. especial, p. 102-110, 2013.

VIEIRA, Ana L. S.; MOYSES, Neuza M. N. Trajetória da graduação das catorze profissões de saúde no Brasil. Saúde em Debate, Rio de Janeiro, v. 41, n. 113, p. 401-414, 2017. 